\title{
Vivencias nocturnas: los antros jarochos a la luz de la comunicación*
}

\section{Genaro Aguirre Aguilar**}

Que sea para “La pequeña”, por todas las cosas grandes vividas, de noche y en los días, en una ciudad que hemos reinventado

Durante los últimos años, los estudios en comunicación han vivido una transformación en el desarrollo de sus objetos de estudios, donde los nuevos ejes temáticos en mucho han dejado de ser sólo mediáticos. Igual, otros temas y novedosas perspectivas teóricas y metodológicas han pasado a convertir a la comunicación en un intenso programa estratégico para el abordaje de las diversas realidades y características de las sociedades contemporáneas. El trabajo que presentamos aquí es una síntesis apretada del trabajo de grado Postal con nota atrás: antro y comunicación en las noches porteñas, donde se busca analizar algunos de los procesos sociales que se viven en centros de diversión nocturna.
During the last years, the studies about communication have suffered a transition in the development of their fields of study, where the new topics, in a great deal, are no longer mass media. In the same way, other topics and new theoretical and methodological perspectives have turned communication into an intense strategic program to study the different realities and characteristics of the contemporary societies. This paper is a brief synthesis of the BA final paper Postal con nota atrás: antro y comunicación en las noches porte$\tilde{n} a s$, where the objective is to analyze some of the social processes in some night clubs. In order to recognize the interaction strategies in such anthropological places, some rites, identity and the territorialization process will be considered as analysis categories.

*Para la realización de este trabajo, se contó con el apoyo del Fondo Nacional Para la Cultura y las Artes. Vaya por esto un agradecimiento.

${ }^{* *}$ Investigador asistente de la Universidad Cristóbal Colón, catedrático por asignatura de la Universidad Veracruzana. E-mail: gaguirre@aix.ver.ucc.mx. 


\section{TRAZOS DE INTENCIÓN}

Desde hace algunos años, la ciudad ha sido un texto sobre el cual se han elaborado múltiples lecturas, que van de lo sociológico a lo histórico, pero donde la arquitectura y la semiótica urbana también han generado sus propios discursos. En este tenor, de un tiempo acá el escenario urbano se ha revelado ante los estudios en comunicación como un "lugar" para observar y comprender algunos procesos y acciones sociales, desde una perspectiva comunicativa, pero enriquecida con lo dicho por la antropología y la psicología social, entre aquellas nombradas primeramente.

De tal suerte, la ciudad, su equipamiento urbano, sus ofertas culturales, sus actores sociales, sus tiempos vitales, han permitido la articulación de un discurso que busca ser una manera "distinta" de abordar lo cotidiano citadino a la luz de las acciones comunicacionales manifiestas por los ciudadanos urbanos. Así, de las mitologías citadinas a la territorialidad barrial; de los centros comerciales como escaparate finisecular a las vivencias y representación de los usuarios de microbuses, han sido algunas de las temáticas convertidas en objetos de estudio para los especialistas en comunicación.

Es en esta vertiente donde se ubica el presente trabajo, cuya versión es una síntesis del proyecto de investigación sobre los mecanismos de interacción en seis antros de la ciudad de Veracruz.

\section{LAS NOCHES DE UNA CIUDAD "PROVINCIANA"1}

Apostarle a la noche en Veracruz, es hacer frente a una gama de ofertas culturales que lo nocturno urbano ofrece al viajero noctámbulo. Y decir esto, es anclar en lo mítico regocijante una serie de idílicos rasgos identitarios que a lo largo de muchos años los saberes ordinarios han ido configurando a propósito de cómo somos por este lugar; dichos incorporados al esquema de representaciones que no se han reducido a los usos y costumbres cotidianos del ciudadano porteño, sino también de aquellos que de oídas saben de Veracruz y llegan por aquí para escabullirse en sus rincones.

En esa dirección, nos dimos a la tarea de realizar una investigación que buscó indagar en lo social, tomando como referencia algunas for-

${ }^{1}$ Para dimensionar las noches jarochas, buscamos categorizarla desde lo cultural manifiesto e incorporado socialmente. Algunos de esos aspectos se plantean a continuación. 
mas culturales que reconocemos como marcadores de identidad que -en buena medida-, dan ruta a las acciones y a los mecanismos de reconocimiento de la vida y la diversión en el puerto veracruzano, atendiendo los espacios para la diversión que las noches y las madrugadas ofertan a quienes cruzan estas fronteras de temporalidad y sentido.

Para reconocer a la noche como un texto construido socialmente, entramos en las regiones de lo imaginario, donde una aproximación a la multiplicidad de textos que la definen, llevó a pensar en las maneras en que el ser humano (de la niñez a la madurez) la percibe, incorpora y reproduce en la música, la literatura, el cine, la televisión; es decir, a considerar a la industria cultural junto a las dinámicas propias de la gente, quienes crean un entramado de representaciones en torno a esta región temporal.

Es aquí, cuando cobra sentido la estética de lo nocturno, emergen y se consolidan las dualidades vitales: del bien y del mal, lo permisible y lo prohibido, lo legal y lo clandestino, son dualidades existenciales que determinan la "norma" social, pero que a lo largo de su biografía personal, los sujetos someten, cada vez más abocados a experimentar con las libertades provocadoras que suscribe en las constantes dinámicas de exploración viarias, aquellas que terminan por convertirse en un descubrimiento vital y polifónico que explica buena parte de las representaciones, prácticas y demás formas de hacerse visible.

En esta dimensión, la noche se convirtió en un texto lúdico, se tensó para ir de la teoría a la práctica, para volver a aquella y hacer inferencias que en el proceder fueron develando el texto nocturno en el que se entró en esta investigación. Así definida, la noche pasó a reconocerse como un constructo sociocultural, donde los usuarios de los antros investigados la ha resemantizado. De tal forma, la carga emotiva con la que han dotado a los seis antros, habla de voluntades a fuerza de la constancia y la creación de esquemas de pertenencia que permiten dotar de una vestimenta especial a cada uno de estos antros.

\section{De Lo CULTURAL Y CONSANGUíNEO COMO PREÁMBULO}

La apuesta inició desde la misma naturaleza del ser jarocho, es decir, por todo aquello que sentíamos lo determina socioculturalmente: la herencia ancestral que corre por la sangre, el cruce de posibilidades vitales que significó lo español, "aderezado" con la sangre de los negros que por aquí comenzaron a llegar años después de la conquista. 
Lo que resulta sin duda profundamente significativo, pues creemos que con ello se abrió la posibilidad de una hibridación cultural que sentó las bases para el reconocimiento de un sincretismo que terminó por dotar de un cierto andar ${ }^{2}$ y las forma de articulación verbal que nos caracterizan, sintetizado en las variaciones melódicas de las que tradicionalmente echamos mano y recreamos de múltiples maneras a la hora de la diversión: en el ritmo de lo cotidiano cobijado por una atmósfera sonora que le da vida a los días en el puerto; en el ulular de los nortes o ventiscas que corren por las calles; en la manifestación plena del gusto por la música bailable que nos despierta todos los días gracias a los microbuses, autos particulares, taxis, casas, oficinas, y otros tantos espacios de socialización, entre los que encontramos a los antros.

Como parte de un trabajo exploratorio de esto, tuvimos que darnos una vuelta por muchos de esos sitios convertidos en lugares antropológicos cuando, al calor de la música (en vivo o "disco"), las bebidas, las botanas, la diversión de los sujetos asistentes irriga por la ciudad $^{3}$ un goce singular. Así, tenemos que los antros pasan a convertirse en continentes regulados, donde la diversión se configura a partir de intereses compartidos, de reconocimiento de los "otros", los mismos que van creando un entramado de sentido a partir de los códigos, los referentes, los significados; los mecanismos de negociación, los procesos rituales, las interacciones emergentes que igualmente van dando identidad a esos territorios tomados por asalto.

\section{Motivos DE UNA BÚSQUEDA}

Postal con nota atrás: antro ${ }^{4}$ y comunicación en las noches porteñas, realizó un análisis a la luz de los procesos comunicativos y los mecanis-

\footnotetext{
${ }^{2}$ Así, por ejemplo, el regodeo lúdico con que caminan nuestras mujeres, es una suerte de objetivación cadenciosa de todo este "filin" cultural que nos identifica, y que se reconoce en muchas de las maneras como nos relacionamos.

${ }^{3} \mathrm{Si}$ bien cuenta la historia, el centro ha tenido una significación especial en el orden económico, político y cultural, pareciera que hoy ha perdido vigencia. Tradicionalmente en la ciudad eran los portales y algunos antros de sus alrededores las regiones que concentraban este tipo de diversión; sin embargo, la periferia urbana ha sido receptáculos de ofertas culturales que tienen un posicionamiento entre algunos grupos sociales; sobre todo en la zona conurbada.

${ }^{4}$ Es importante señalar que la concepción de antro para esta investigación se elaboró a partir de los usos comunes que los usuarios de la noche le dan a esos espacios de diversión donde la música, el baile, las bebidas, conjugan marcadores identitarios
} 
mos de interacción allí generados. Los encuentros y desencuentros vividos en los antros seleccionados, tuvieron que ver con una cotidianidad jarocha, donde se producen y re-producen formas de vida que van construyendo ciertos rasgos de identidad y algunos procesos de territorialización; donde sujetos y objetos multiplican sus relaciones para configurar un texto cultural, cuya porosidad da cuenta de una gramática cultural sobre la que es posible leer para comprender un tanto lo que son los usuarios en tales lugares.

El referente empírico ${ }^{5}$ que cobijaba esta pesquisa, tenía que ver con una lectura a priori que suponía la emergencia de maneras de diversión ${ }^{6}$ donde lo permisible abría la oportunidad para que nuevos actores se sumaran a la trama nocturna, lo que resquebrajaba la concepción tradicional que se tenía de la diversión en esos espacios, ahora resemantizados.

\section{AlgunOS RASGOS EPISTÉMICOS}

Hecha esa operación, inició la búsqueda llevando a cuestas una serie de líneas temáticas relacionadas con procesos de negociación, defensa de territorios históricos, ${ }^{7}$ configuración de identidades, mecanismos de socialización.

de tales sitios. El consumo cultural alrededor de estos lugares, muestra que el antro ha dejado de tener un cariz marginal y de clandestinidad, tal como dan cuenta las concepciones de los diccionarios y las representaciones que pudiéramos tener. Hoy lo light suple a lo rasposo y de mala reputación.

${ }^{5}$ Este supuesto que trazó las primeras rutas de aproximación, llevó por distintos rincones del Veracruz de noche: de las taquerías ubicadas en la zona conurbada de la ciudad porteña y Boca del Río, a los cafés puestos de moda en los últimos años; sin dejar de lado los espacios públicos institucionalizados por la tradición que, sin embargo, los nuevos actores pareciera han "olvidado", trazando una geografía simbólica que esboza sobre la ciudad rutas de pertenencia y diferenciación, reafirmando con esto lo generacional. Lo que vino a continuación, fue diseccionar estratégicamente este entramado cultural.

${ }^{6}$ La concepción de emergencia, viene del reconocimiento que supone la visibilidad de los grupos femeninos para tomar por asalto la noche. Lo mismo aquí que seguro en otros lugares, adolescentes, jóvenes y adultos han iniciado un cruce generacional que pone a dialogar referentes, historias y concepciones de vida distintas, que se reproducen significativamente en los reductos que la ciudad concede para la diversión.

${ }^{7}$ Hago referencia a lo histórico, tomando en cuenta que, como sujetos sociales, tenemos una serie de referentes que configuran parte de nuestras percepciones y representaciones. En este sentido, tradicionalmente también es posible reconocer como 
En este momento, las preguntas circunstanciales de meritita inspiración a partir de una "realidad" identificada, pero que distaba aún de ser leída en términos fenomenológicos, eran: ¿quiénes son los agentes sociales que acuden regularmente a los antros jarochos?, ¿qué hacen en sus estancias nocturnas?, ¿qué tipo de usos le dan a determinados lugares?, ¿qué implicaciones sociales tienen sus prácticas culturales?, ¿es posible hablar de actores emergentes y/o de estructuras de significación compartida en los distintos antros? Como podemos dar cuenta, más allá de un ordenamiento epistemológico estas preguntas fueron una suerte de detonadores en nuestra actitud natural; interrogantes tentativas que más tarde provocaron y orillaron a la configuración de nuestro objeto de investigación: las formas de articulación y reproducción de las prácticas culturales en los escenarios nocturnos, para comprender las estrategias de significación de los agentes sociales en la determinación de sus acciones, interacciones y procesos comunicativos durante sus estancias en los antros de la ciudad de Veracruz. Para ello nos planteamos una pregunta rectora: ¿Qué prácticas culturales dan sentido a las formas comunicionales y de interacción social emergentes en seis ofertas de diversión y esparcimiento público durante las noches de fin de semana en la ciudad de Veracruz? ${ }^{8}$ A partir de esto, la ruta seguida tuvo que ver con un supuesto construido después de la energía que representó andar las calles y los rincones de la ciudad de Veracruz: lo bebido, sentido y vivenciado en estas regiones, era permeado por nuestra premisa mínima de trabajo: la oferta y el consumo cultural nocturno en el puerto de Veracruz, eran fenómenos propios de lo urbanístico, donde lo ideológico moderno incidía en las formas de vida y las prácticas de lo cotidiano.

Como parte de los implícitos, poníamos en perspectiva la categoría de oferta cultural, pues sentíamos que ésta había alterado las formas tradicionales de diversión de las noches citadinas. ${ }^{9}$ Éste era un aspecto

"personajes" históricos a aquellos agentes que desde siempre han sido "dueños" de esos centros nocturnos. Nos referimos sobre todo a las prostitutas, meseros, homosexuales, padrotes, cantineros, quienes de pronto se han visto compartiendo sus espacios con otros actores, antes, quizás, impensables: niñas bien, jovencitos guapos, familias enteras, entre otros. Ante esto, ¿cómo han respondido para defender ese territorio?

${ }^{8}$ Junto a esta interrogante, otras complementarias: ¿qué factores socioculturales han generado una redefinición de los roles típicos de los personajes nocturnos en el puerto de Veracruz?, ¿cuáles son los nuevos sentidos y formas de socialización nocturna que se esbozan en la ciudad de Veracruz, como formas emergentes de interacción?, ¿de qué manera los "personajes" nocturnos comparten, negocian, establecen, delimitan, construyen sus identidades y definen el territorio en un antro?

${ }^{9}$ Esto ante lo evidente que es ver cómo en los últimos 15 años, Veracruz y su zona 
que no podíamos obviar en una investigación donde lo cotidiano permeaba, pero también la configuración de saberes a partir de la apropiación y uso de esos espacios, que la praxis social reconoce como antro y que los usuarios-actores convierten en un escenario donde se configura una gramática cultural, que debía considerarse para acercarnos al conocimiento "profundo" de sus circunstanciales vivencias nocturnas.

\section{LA SÍNTESIS DE UNA ESTRATEGIA}

Cumplida una primera aproximación al territorio citadino, para el análisis de las con(o)currencias en seis antros jarochos, ${ }^{10}$ diseñamos un mapa nocturno integrado por tres zonas: Centro, donde se seleccionaron La Tasca Colonial y El Rincón de la Trova, cuyas unidades fueron de análisis de consumo y formas de diversión, identidades y procesos de territorialización, respectivamente; de la Gran barra nocturna, la Disco Ocean y Chévere Cocó, antros donde trabajamos sobre actitudes y formas de diversión, además de rituales, y finalmente, de la zona Marginales en el centro, Kokai y Lencería, los observables de análisis fueron los comportamientos y procesos de negociación, para ambos lugares. Cabe señalar que para la definición de estas regiones nocturnas, se consideró lo geográfico, el tipo de oferta cultural y lo simbólico conjugado. ${ }^{11}$

conurbada con Boca del Río ha extendido su trama urbana, misma que llevó al asentamiento de un corredor turístico donde las comidas fast-food y los centros de diversión nocturna han incrementado su presencia. Ante esto, fue reconocible que lo urbano, entonces, era un factor que incidía en algunas formas emergentes de interacción social en el puerto jarocho.

${ }^{10}$ Es importante señalar que, después del trabajo de exploración nocturna realizado, la primera selección correspondió a 12 antros, mismos que conjuntaban la diversidad de ofertas que las noches de Veracruz ofrecen a sus usuarios. No obstante, los primeros diálogos que tuvimos con la primera asesora, nos señalaron la necesidad de replantear el número, pues sería difícil cumplir con los tiempos que exigía el programa académico del posgrado. A continuación, acordamos ubicar en las tres zonas diseñadas para el trabajo, dos unidades de observación por cada una; mismas que serían aquellas las que respondieran a las ofertas más significativas reconocidas por los propios usuarios que en entrevistas in situ habíamos realizado para aquel entonces.

${ }^{11}$ A partir de las representaciones sociales, se consideró lo tradicional y lo moderno en materia de diversión. Así, como parte de lo "tradicional", seleccionamos dos antros ubicados en el primer cuadro de la ciudad: el primero en Los Portales y el otro en La Lagunilla, uno de los callejones tradicionales de la ciudad; a continuación, dos sitios de la llamada "Barra más grande del mundo" (así se le conoce al bulevar jarocho), el primero, una disco y el otro, un salón de baile; mientras que 
Para la realización de los fundamentos metodológicos, se consideró la perspectiva cualitativa, tomando como tecnología para el trabajo empírico la observación directa y entrevista con informantes ocasionales (usuarios, meseros, bailarinas, taxistas, etcétera), siendo regidos para la sistematización de información por las propuestas de Spradley (1980) y sus dominios culturales, para el trabajo analítico de la información recogida en campo, y a Edward de Bono (1996) y su lógica fluida, para la representación gráfica del análisis, donde convertimos sus ámbitos de flujo en ámbitos comunicativos. Por último, para el análisis, interpretación y textualización, nos asistimos de la hermenéutica profunda según propuesta de Thompson (1996) y Geertz (2000), junto a quienes entendimos que el análisis de la vida cultural que queríamos hacer, eran descripciones interpretativas hechas como investigadores, a partir de una textualización de los fenómenos observados en la investigación. ${ }^{12}$

\section{APUESTAS TEÓRICAS}

Como queda explícito en el tipo de discurso hasta ahora manejado, si bien es cierto que la perspectiva de abordaje se piensa desde la comunicación, la sustentación del corpus teórico-conceptual se nutre de una serie de términos emanados de las ciencias sociológicas, antropológicas, históricas que, en este trabajo, convertimos en categorías básicas ${ }^{13}$ para llegar a la abstracción propia de nuestra investigación, que partía de los usos comunes al terreno de lo académico-científico: sociedad, representación social, interacción, socialización, comunicación y cultura, fueron categorías primarias sobre las que se fundamentó mucho de lo trabajado.

Así, sociedad es un conglomerado humano que comparte intereses en común y mantiene una cierta cohesión al interior que le permite un funcionamiento, lo que supone un sistema constituido por subsistemas

para la última zona se consideraron los aspectos "marginales" y "simbólicos" citadinos, que llevaron a reconocer como "emergente" el tipo de oferta de diversión: la desnudez femenina como continente de deseos instantáneos.

${ }^{12}$ Tendría que aclarar que el espacio con el que ahora contamos nos imposibilita mostrar en extenso cómo se construyeron los modelos de análisis, interpretación y textualización del trabajo empírico. Quedan aquí algunos apuntes pertinentes, a penas (de dificultad).

${ }^{13}$ Cabe señalar que, en aras de la síntesis, sólo referiremos aquellos conceptos más significativos para el trabajo, pues, se debe decir, el proyecto llevó a definir otros conceptos tales como: espacio, lugar, ciudad, sociedad, ritos, entre otros que ahora no hemos considerado por la naturaleza de este texto. 
que trabajan con interdependencia. Si bien es cierto que se puede reconocer una mirada reducida en esta concepción al trasladarla a las sociedades contemporáneas, también lo es que permitió tener una certidumbre sobre dos aspectos fundamentales: las acciones y los sujetos, en tanto elementos concomitantes que objetivan, estructuran y dan sentido a aquélla.

Mientras, las representaciones sociales las entendemos como los productos del proceso social de representar, donde la referencia serán tanto el proceso como el producto de hacer que unos signos hagan las veces de sentidos (O'Sullivan et. al. 1997). Así, la noción de representación social fue útil para esta investigación por cuanto unifica lo que a simple vista puede parecer un conjunto inconexo de piezas y fragmentos conceptuales. Compartiendo junto a los autores la certeza de que las representaciones son los procesos por medio de los cuales se establecen las formas de percepción de la realidad.

A partir de reconocer los antros como sitios donde se establecen un puñado de maneras para actuar y representar los roles convalidados por la costumbre y donde el tejido societal da cauce a una serie de acciones articuladas y hechas sentido a partir de las interacciones que allí se desarrollan, el antro es un lugar del estar, pero también del practicar. Por ello, al decir interacción social (tanto no focalizada como focalizada), estamos hablando de un proceso que vierte sobre el tiempo y el espacio la capacidad de pensamiento y acción del ser social, misma que permite precisamente la integración a partir de la relación con el o los demás actores sociales, en el proceso y objetivación de sus acciones cotidianas. Hablar de interacción social, pues, es encontrar los lugares, las zonas convertidas en campos de comunicación, donde los actores desarrollan sus haceres, articulan sus maneras de manifestarse presentes, intercambiando sentido y significado.

Así, durante este juego de acciones los sujetos comunican significados a otros, quienes intervienen y orientan sus respuestas según la interpretación de la situación, lo que hace posible un proceso de influencia mutua. Ante ello, la interacción "se fundamenta en la apertura de los sujetos a la comunicación y a la aceptación de sus reglas [...]. La estructuración de la interacción organiza [...] la comunicación acerca del comunicar" (Wolf 1994: 50), lo que quiere decir que cada ocasión de encuentro en un antro abre la posibilidad de establecer mecanismos de relaciones en común acuerdo.

Junto a estas categorías, la comunicación igual fue una herramienta conceptual en el trabajo, pues desde esta perspectiva analizamos el 
sentido y significado de las con(o)currencias o actos de co-presencia en los antros, a partir de los niveles de intervención, producción, distribución e interpretación de signos sociales vistas a la luz de las acciones objetivadas de los usuarios nocturnos. Así, apelando a la dimensión simbólica, desechamos la definición que supone el envío de mensajes de un emisor a un receptor (la perspectiva informacional), para reconocer a la comunicación como un proceso de negociación e intercambio de sentido, "donde los mensajes, gente perteneciente a una cultura y 'realidad' interactúan para que se produzca un sentido o un entendimiento" (O’Sullivan et al. 1995: 66-67). Así, sumados a Giddens (1998), la comunicación también la reconocemos como el punto generador más acabado de lo social: la interacción.

Para dar por concluida esta aproximación, juzgamos pertinente recuperar la propuesta conceptual de cultura que nos proponen autores que piensan en la dimensión simbólica para comprender lo social. De tal suerte, más allá de la concepción evolucionista, de Thompson (1998) a Geertz (s/f), pero lo mismo de Jiménez (1996) a González (1994) y Bourdieu (1990), la cultura la reconocimos como una evolución significativa donde, si bien es cierto que al inicio era sinónimo de civilización, hoy la dimensión simbólica nos dice que "es el patrón de significados incorporados a las formas simbólicas -entre las que se incluyen acciones, enunciados y objetos significativos de diversos tipos- en virtud de los cuales los individuos se comunican entre sí y comparten sus experiencias, concepciones y creencias" (Geertz en palabras de Thompson 1998: 197).

Desde estos terrenos, elaboramos un concepto propio para la investigación, considerando el campo de prácticas y las estructuras de significación emergente, los cuales consolidan formas de vida. Así, es posible determinar la cultura como ese corpus de signos sociales incorporados y hechos sentidos objetivados sobre los que operan las acciones de los distintos sujetos sociales; mismos que determinan su trayectoria y la forma de vida a partir de una compleja articulación.

\section{DE SITIOS, DIVERSIÓN Y QUERENCIAS NOCTURNAS}

Lugar desde el que se generara esta investigación una tarde de hace unos cuatro años, Los Portales de Lerdo (como oficialmente se llama esta zona) es un sitio de tradición en el puerto. Allí se encuentran reunidos una decena de antros que, aun cuando presentan el mismo tipo de oferta 
cultural, también lo es la existencia de rasgos distintivos, entre uno y otro lugar. Sin embargo, tenemos que decir que en los últimos años se ha podido constatar el posicionamiento de estos lugares entre las clases acomodadas y, particularmente, entre los jóvenes, donde la presencia de mujeres se ha incrementado. Así, en un antro como La Tasca Colonial, se determinan algunas mecánicas de interacción que dan sentido y configuran identidades entre los comensales y sus prácticas de socialización.

Desde la observación de los accesorios culturales al equipamiento sígnico, ${ }^{14}$ es posible establecer formas comunicativas que conducen a una cierta distinguibilidad ${ }^{15}$ en este antro. La vestimenta y otros objetos culturales (beepers, celulares, tipos de bebidas, cajetillas de cigarros, etc.), son elementos que articulan una trama de significación, complementada por la objetivación de sus acciones: desde miradas hasta sonrisas que "glamurizan" los momentos entre los chicos "bien" y las familias que allí recuperan el ideal "matrio"16 (Giménez 1992) a lo que se consume: de botanas de la casa o "chucherías callejeras", a platillos elaborados propios de la "madre patria"; de las cervezas light a las botellas de brandy, pasando por algunos aperitivos.

Cabe señalar que, en el caso de la interacción grupal, también fueron observables las maneras en que se generan y determinan los procesos comunicacionales según el tipo de grupo social. Con esto queremos mencionar, por ejemplo, cómo en el caso de los grupos de jóvenes, la agenda discursiva fluye horizontalmente; es decir, las intervenciones en las pláticas crean una dinámica aun cuando sea reconocible que -en aquellos formados por parejas-, el hombre dominara los giros sobre los que versa la charla: intervenciones, exaltación gestual, entre otros aspectos.

${ }^{14}$ Llamamos así a todos aquellos elementos que se accionan en la lógica social propia de este antro: miradas, gestos, sonrisas, posturas, caricias, entre otras "prótesis" culturales observadas en este antro.

${ }^{15}$ Al hablar de distinción queremos referirnos a la identidad, donde hacemos referencia a las características manifiestas entre los distintos grupos sociales que allí coinciden: jóvenes, adultos, familias, parejas, quienes construyen un escenario discursivo propio, objetivado en las maneras como hablan, cómo gesticulan, qué dicen; es decir, cómo echan por delante un cuerpo textual válido y con sentido para cada grupo. Aquí sólo generalizamos.

${ }^{16}$ Cuando decimos esto, pensamos en el mismo nombre del antro, pues en una dimensión geosimbóca, el mismo nombre potencia esto, además de los motivos decorativos que adornan el sitio: piezas de jamón serrano, carteles taurinos y una iconografía española que identifica los accesos a los servicios sanitarios. 
Lo anterior sirve para comentar que para el caso de las familias, sean de los sectores medios o altos, el patrón de comportamientos es en una dirección, al asumir el "jefe" de familia una posición que le confiere lo social-cultural. En este sentido, los flujos comunicacionales se acercan más a lo vertical (informacional en términos comunicativos), aun cuando en una u otra familia, pueda estar otro hombre "externo": novio de la hija o algún otro sujeto social de estas características.

Otro aspecto característico de este sitio, es que de pronto se vio "asaltado" por los públicos juveniles "bien", quienes comenzaron a encontrar en este lugar una suerte de parada nocturna, para de allí saltar a otros lugares de diversión ubicados en la zona sur de la ciudad, justo donde hace "encuentro limítrofe" la ciudad de Veracruz con Boca del Río. Los puntos de contacto tienen que ver con la "toma" de las mesas ubicadas en la parte externa del antro. Allí sentados, figurines ellos y chicas de magazine ellas, estos jóvenes (en un rango de edad de los diecisiete a los veinticinco años), convierten este sitio en un escaparate nocturno donde los vestuarios de revistas del corazón, las poses de TV y los rostros reinventados por el fino maquillaje; con las cabelleras relucientes de gel en ellos y cuidadosamente "talladas" en ellas, son estilos de ser que signan una estancia que no va más allá de las dos horas, donde los delicados aromas serpentean al salir de sus cuerpos y "ropajes". Más tarde, a punto de caer la media noche, inician la fuga para irse a divertir a otros antros, aquéllos donde, al dar las doce, las puertas abiertas posibilitan otras maneras para consumir la noche.

Sí, para los jóvenes que acuden a La Tasca Colonial, el sitio es apenas un lugar de primer contacto, después viene la diversión en extenso en otros lugares: las discos o los videobares; para que, sobre la madrugada, coronen la noche a la luz de los arbotantes que flanquean el bulevar porteño, ${ }^{17}$ el mismo que les permite una atmósfera de calidez nocturna con la llegada de la brisa marina hasta ya entrada la mañana.

${ }^{17}$ Por aquellos días de la investigación, el gobierno panista tuvo la iniciativa de prohibir el consumo de bebidas en las vías públicas (particularmente en la llamada "Barra más grande del mundo"); no obstante, los usos y costumbres terminaron por imponerse. El desconocimiento de una tradición histórica por parte de la administración panista, terminó por exhibirlos. Una práctica cultural de tantos años era difícil que fuera sometida por una decisión sin que los ciudadanos de todos los estratos "levantaran" sus vasos de licor para protestar. Por cierto, es curioso, pero esta efervescencia social en torno al uso y apropiación de los antros, comenzó a ponerse de moda a la llegada de la primera administración panista entrados los noventa. 
Como se puede ver, en La Tasca Colonial las prácticas culturales presentes tienen una manera particular de establecerse a partir de cada uno de los grupos sociales observados; así, las formas comunicacionales y de interacción plantean esquemas significativos de diversión y esparcimiento en ese antro. Esto supone una emergencia de sistemas diversos que dan soporte a los constructos de significación que es posible encontrar aquí.

Por otro lado — de la misma zona — hablar de El Rincón de la Trova es dejarse ir con el sentido y lo emocional de los encuentros y las interacciones; es reconocer una cierta cofradía, un enclave que de pronto pareciera críptico, pero que por su misma configuración y su gente se abre a este proceso de confluencias sociales, rítmicas y de alteridades: el encuentro con el Otro, el mismo que tiene tantas diferencias con nosotros, como similitudes tenemos con él, al ritmo del son y los recuerdos objetivados en las vestimentas de quienes allí concurren, para escuchar los viejos sones cubanos.

Si no fuera así, cómo explicar ese ritual iniciado al caer las diez de la noche de cada fin de semana, cuando da inicio una peregrinación por calles y avenidas del centro, hasta dar con el corazón mismo de ese reducto convertido en santuario para los soneros de corazón. Y ese conciliábulo de hombres y mujeres erigido a propósito del matrimonio apresurado entre Changó y María de Guadalupe, da cuenta de un estilo para vivir las noches porteñas.

Igualmente, El Rincón de la Trova es un lugar de ruptura con la modernidad, donde la vuelta al pasado pone al servicio de quienes se quieran divertir, un repertorio de música para la nostalgia, la misma que termina por forjar una especial forma de identidad pocas veces vista en otros lugares a partir de la apropiación física y simbólica que se hace de este antro.

$S u$ gente ha hecho de este espacio más que un centro de reunión los fines de semana. Es la ocasión para establecer relaciones con los "pares" que acuden allí, no sólo a través de lo que escuchan, sino también a la evocación vehiculada por ese sonar de los cueros y el tresillo para, con ellos, recobrar una memoria que no ha desaparecido; todo lo contrario, cada fin de semana se manifiesta presente.

El Rincón de la Trova, y su gente, son la constancia del sentido y las formas de operar de aquellas prácticas culturales particulares que se erigen a propósito de un espacio consagrado al recuerdo. Es designación de un territorio hierático que un puñado de asiduos participantes han 
construido para no sólo estar sino también ser a través de este antro que cincela en el cuerpo y la mente una cierta "distinguibilidad". Los allí reunidos, en comunión, sin duda tejen interacciones a partir del sentido de pertenencia al que necesariamente lleva el pensamiento reflexivo una vez incorporadas las condiciones espaciales y temporales observadas.

A continuación haremos algunas puntualizaciones sobre la segunda de las zonas trabajadas, donde los ritos y actitudes observables fueron analizados para comprender las maneras de socialización en Ocean y Chévere Cocó. Con estas categorías puestas en marcha durante algunas noches de fin de semana, pudimos reconocer ciertas estrategias que signan sobre estos entramados culturales, rasgos de intervención social que devienen identidades construidas y vivenciadas en tales antros.

Cual pasarela trazada sobre el concreto, iluminada por luces neón y las lámparas que irradian luz desde las alturas, algunas docenas de ojos se asoman para tomar por asalto el asfalto y las banquetas de las noches jarochas, frente a la disco Ocean. Una algarabía manifiesta en aquellos rostros y cuerpos juveniles que crean un peregrinaje hasta dar con aquel salón de baile "moderno" que, si bien hoy no es lo que fue ayer, ${ }^{18}$ sigue siendo un sitio importante para reconocer en él una opción dentro del campo de diversión que ofrece la ciudad a estos sectores sociales.

Cobijados por un "ingenuo" glamour que dictan las revistas de magazine y los escaparates de la última moda, ellos y ellas apelan a estilizados cortes de cabellos que decoran con un brillo "humedecido" a fuerza de $\mathrm{gel}$. De allí a sus vestimentas, conocemos colores, texturas, cortes, accesorios; pero igual sonrisas, comentarios, andares que van configurando una gramática porosa que luego se traslada y enriquece en el interior de la disco.

Ya dentro, la penumbra y el sonido alcanzando decibeles altísimos, obligan a establecer estrategias para comunicarse. Sin abandonar las formas y cosas que los identifican, los jóvenes asistentes van tomando por suya la mesa-espacio-territorio que les corresponde: los hay quienes se dejan llevar por el acomodador hasta situarlos en una mesa que siempre será estratégica y de cara a los acontecimientos; pero también aque-

${ }^{18}$ Cabe señalar que en sus inicios, a mediados de los ochenta, esta disco fue sitio por antonomasia para lo sectores "bien" del puerto. Sin embargo, con los noventa, el ensanchamiento en este tipo de oferta, que tuviera su experiencia anterior en la efervescencia setentera, convirtió a Ocean en una opción más entre otras. Para esta investigación, fue considerada a partir de estos referentes que, de alguna forma, siguen confiriéndole un capital cultural entre los jóvenes veracruzanos. 
llos que prefieren situarse en una suerte de muro que circunda la pista. Hombres y mujeres, por grupos genéricos o heterodoxos, se adueñan de ese circuito territorial.

Allí reunidos, comienzan a tejer códigos y mecánicas de interacción que devienen sentido: dedos extrayendo cigarrillos de las manos de ellas, encendedores zippo o bic que en su operación manifiestan un intento por sofisticar una acción mínima, para ser coronada por una exhalación profunda que luego deja escapar el humo por unos labios apenas abiertos: corrientes finas y círculos crean una atmósfera nebulosa en mesas que signan momentos, mientras bocas, ojos, manos construyen formas gestuales para transmitir emociones y momentos.

Cuando inicia el baile (justo a la media noche, después de una presentación espectacular por parte del "diyei”, parejas (hombres-mujeres, mujeres-mujeres) se encaminan a la pista, apenas palabras y sí, muchas miradas, movimientos pélvicos donde cabalga un erotismo, sonrisas construidas a fuerza de una coquetería cándida, pero por ello más provocadora, lo cierto es que en esta disco, cumplidores siempre del rito y la formalidad dancísticas modernas, las columnas formadas por los "chicos" y las "chicas" son la reiteración semantizada y cultural de un orden contingente. Es decir, en este acto de objetivación del ritmo hecho cuerpo, un sector "tradicionalmente" viviendo contra la regla, allí reunido establece sus estrategias para asumirse partícipes y co-correspondidos por convencimiento. El baile y su "ordenamiento" social, es la reproducción de coincidencias y acuerdos que dura mientras los sujetos y sus circunstancias (tiempo y espacio) lo determinen; para después volver al caos y reinventarlo cada ocho días.

Así, las noches de disco en Ocean son una reinvención de los tiempos generacionales: desde adolescentes a jóvenes, los allí convocados echan a andar comportamientos ritualizados y ritualizables (donde lo sexual inmaculado convive junto al temor a algún tipo de contagio) que fracturan esquemas social y tradicionalmente "impuestos". Es decir, aquí los tiempos anuncian cambios significativos en lo permisible o no, particularmente en lo que siempre ha sido un tipo de diversión para "mayores" de edad. El consumo y las prácticas culturales como el baile, las bebidas, los asistentes mismos, así lo dicen.

Por su parte, en el caso de Chévere Cocó, sin pretender un análisis comparativo absoluto, es posible tender un puente reflexivo para encontrar constantes similares en las formas de diversión. Del baile a las maneras de galanteo (flirteo, coqueteo, ligue) entre el salón de baile salsero 
y la disco existen diferencias importantes. Allá el orden, aquí un desorden aparente.

Tanto en su horario de llegada como en la distribución del espacio y su mobiliario, Chévere Cocó se muestra distinto: abierto los ocho días de la semana, la llegada a este antro es apenas marcada las diez de la noche, para que desde esa hora, a lo largo de la noche y la madrugada se convierta en punto de llegada de aquellos noctámbulos deseosos de divertirse.

Mujeres, hombres, jóvenes y "viejones", son el grupo social que prefiere acudir a bailar salsa ${ }^{19}$ en vivo en este antro. Venidos de oficinas y agencias portuarias, de empresas medianas y dependencias municipales de menor rango, los comensales allí presentes establecen una estrategia de convivencia donde una serie de acciones revelan comportamientos consensados: flirteos, ligues que, a diferencia de la disco, se abren "sabrosos" a la posibilidad del regodeo sexual. El tipo de baile y el "en cortito" de esta manifestación corporal, permiten el intercambio de flujos sensitivos: roces y sudores, en medio de una atmósfera en penumbras que se enriquece con los sonidos rítmicos de la música "guapachosa", permiten el "agasaje" contingente. Pues si bien es cierto que muchos de los asiduos a este lugar son parejas o grupos de conocidos que allí se hacen "pares" en el baile, también lo es que el buen bailar tanto de mujeres como de hombres, abre la posibilidad para el encuentro "negociado" y disfrutar de unas horas entre desconocidos allí "re-conocidos" por la forma en que manifiestan su goce por esta música.

Tanto el contacto físico como el "montaje" del decorado, plantean una condición distintiva en este antro, pues Chévere Cocó es un lugar para la gente de clase media y, como tal, no lo niega: dentro de lo marginal, aquí sigue siendo posible la convivencia entre las meseras y los asistentes, pues aquel que no lleva pareja o no lo desea, puede ponerse a bailar con las chicas que lo mismo atienden las mesas que a los hombres que con ellas deseen danzar. Como es de imaginar (y de observar), la

${ }^{19}$ Cabe señalar que los días y las noches de salsa en el puerto son un tipo de oferta cultural que tiene como característica la música en vivo. Grupos locales que preferentemente tocan en el conjunto de lugares que ofertan esta opción bailable, son quienes ejercen una presencia significativa en los antros; pues otras opciones posibles (rockeros, chunchaqueros [quienes tocan un tipo de música tropical cuyas bases rítmicas son muy simples. El nombre chunchaca es una suerte de onomatopeya generada a partir del reconocimiento de los sonidos reguladores de esta propuesta música: chun-cha-ca-chun-cha-ca], baladistas, trovadores), aun cuando tienen sus espacios, no lo son tanto como aquéllos. 
opción facilita el proceso de negociación para iniciar un juego cargado de sexualidad que llega hasta donde la mesera lo permita, pues allí no se prostituye, pero sí se intercambian humores y porosidades consentidas.

La estrategia de convivencia tiene que ver con formas de comunicación que potencian los códigos de significación, donde lo verbal, pero sobre todo lo gestual/corporal, junto a otros elementos culturales incorporados, como pueden ser los accesorios, vestidos, entre otros, conducen y enriquecen las formas de interacción en un salón de baile donde la música en vivo es un aliciente en esa integración sociocultural.

De la tercera zona, a la que llamamos de marginales en el centro, estableceremos un abordaje que busque conjugar las lógicas sociales allí presentes. Entendemos que esto pudiera ser un "atentado" metodológico, sin embargo, la pertinencia la hallamos a partir del referente obligado: lo sexual corporeizado en dos antros donde la desnudez femenina "revienta" el imaginario masculino, que se ancla en los deseos apresurados que convocan los hombres que acuden a un table dance y a un antro donde las mujeres se exhiben en lencería.

Kokai y Lencerías ${ }^{20}$ son de esas maneras de diversión cuasi propias de lo contemporáneo, ${ }^{21}$ si tomamos como referente el periodo de aparición y cómo se fue haciendo extenso este tipo de oferta cultural, lo que también pensamos tuvo que ver con el ensanchamiento de lo permisible. Así, la aparición de muchos de estos antros "teiboleros", viene arropado por ciertas condiciones sociales y culturales que tienen que ver con lo público/privado, lo prohibido y clandestino como constructo ideológico para asumirse parte de una urbe moderna. Es decir, entendemos esta propuesta de diversión como un fenómeno propio de las ciudades, y si éstas son puerto, cuanta más razón tendría su aparición, crecimiento y posicionamiento en el gusto de los hombres veracruzanos.

${ }^{20}$ Debo mencionar que, para la parte última del trabajo de campo, este antro cambió de giro, convirtiéndose por completo en un table dance.

${ }^{21}$ Aquí sí es importante asumir que la referencia es al puerto de Veracruz, una ciudad que si bien pudo ser la puerta de entrada a la modernidad (si tal cosa llegó efectivamente), en materia de ofertas culturales la desnudez explícita para regocijo de los comensales no tiene historias anteriores a ésta. Reconocemos que a través del cine gringo y mexicano pudimos tener idea de este tipo de propuestas para la diversión, pero las ciudades de los estados tienen sus propias lógicas y memorias; por lo demás, el país no se reduce a la ciudad de México, tal cual históricamente lo ha pretendido reducir el cine posrevolucionario urbano. El primero de estos sitios teiboleros, tal cual se le conocen ahora, fue abierto a finales de los ochenta. 
En el imaginario social y perceptivo, es lugar común pensar que los "teibol" son sitios donde acuden hombres con orientaciones "oscuras". Sin embargo, lo visto aquí, más allá de juicios morales, deja al descubierto una sintomatía que refleja algunas particularidades propias de lo masculino. Decimos esto pensando en la reafirmación de una condición evidentemente presente en estas regiones de la diversión nocturna: la mujer-objeto oscuro de deseo.

En efecto, tanto en Kokai como en Lencerías el deseo se configura desde las miradas que surcan el espacio para ir a posarse en aquellos cuerpos ofrecidos, lumínicos y eróticamente puestos a "disposición" de un público que hurga en la noche para dar con la mujer que "desciende" de los "cielos" imaginados (en este caso manifiesto en el descenso de una chica que, desde las alturas de un tubo de acero, va y posa con suavidad su carne desnuda).

Así, en Kokai las "Barbys", "Samanthas", "Jenifers", son la objetivación de unos deseos cumplidos. Allí están ellas para hacer posible los sueños de un puñado de hombres que, en medio del licor y una algarabía, dejan escapar sonrisas, bromas, gestos, gritos, mientras tales mujeres danzan cadenciosas en una pasarela hasta terminar una melodía. Lo que a continuación viene, no es otra cosa que una exhalación libidinal cuando ellas comienzan a desprenderse de sus diminutas ropas. He aquí que el sexo desnudo, el pubis al descubierto y unas "chichis" que danzan rítmicamente, convocan algunas miradas, mientras otras huyen para dar con aquella mujer que a horcajadas sobre un tipo se mueve buscando provocar ansias, mientras él, impedido por la circunstancia, se queda con las ganas de tocar, de ir más allá de lo permitido por la misma lógica del lugar. ${ }^{22}$

Ello no ocurre en Lencerías, donde el contacto físico es la entrada al terreno de lo imaginal cumplido. Allí, las dinámicas de socialización se regodean y configuran a partir de la compraventa de momentos hechos piel, de cuerpos "sublimados" por el lugar común, ante los clisés manifiestos en negliges, baby doll, ligueros y otro tipo de lencería; donde los colores rojos, negros, blancos de encaje y sobrepuestos en pieles más bien morenas, al aliento de luces neón, crean figuras fantasmagóricas cabalgando sobre un apresurado erotismo.

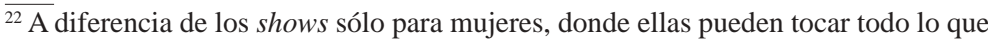
quieran, en los table dance está prohibido que el hombre toque. De lo que se trata es de dejarse hacer. 
De tal suerte, esta visualización de la carnalidad es la proyección de las ansias negociadas, donde las mujeres y los hombres revierten la norma pública, para compartir ese espacio antropológico — que se configura a partir de mecánicas de interacción, donde referentes culturales pasan a ser el conjunto de códigos y signos que estructuran y dan sustento a las interacciones-, en una trama de sentido, de piel a piel, de emoción a emoción, de sujeto-objeto-sujeto; todo canalizado en lo que se consume y vive en un antro que antepone lo sexual apresurado, para repensar la diversión.

\section{LA VIDA ES UN...}

Con todo esto, estaríamos reconociendo que los lugares mencionados pasan, de ser meros continentes físicos, a arenas de confrontación de sentidos donde la diversión, el baile, el flirteo, el consumo de licor; los hombres y las mujeres; los jóvenes y los viejos, solos o en familia, se determinan a partir del establecimiento de acuerdos y consensos socioespaciales. Es decir, el puñado de lugares para ir a beber, divertirse, platicar o bailar salsa, chun-chaca, merengue, música grupera, cumbia, disco y demás propuestas musicales, conjugan distintos niveles de expresión cultural capaces de dimensionar lo cotidiano, particularmente los fines de semana. Esto no es otra cosa que un texto donde la práctica social determina acciones que devienen sentido y que ahora los tomamos como textos culturales que hemos buscado comprender en un trabajo de investigación.

Como es de imaginar, el maquillaje, los vestidos bonitos y bien apretaditos, la piel, el cabello sobre los hombros de ellas; la camisa y el pantalón de pliegues, la barba afeitada, el pelo recortadito, algunos y largos otros, de ellos, son una suerte de marcadores culturales que emergen y glamurizan las siluetas pintadas sobre el fondo neón, que se entrecruzan con todo lo sonoro y circunstancial de los lugares donde los jóvenes objetivan sus prácticas culturales citadinas. Pero igual en el caso de los adultos y los viejos que toman por asalto la noche, envestidos con sus mejores galas (de pañoletas y accesorios que recuerdan viejas películas mexicanas, a guayaberas o camisas estampadas y pantalones bien alineaditos en los señores) para hacer de los antros un sitio de convivencia, sí, pero igual de pertenencia y reconocimiento social.

Asumimos una condición de emergencia en las formas relacionales y en los usos que se establecen en los antros estudiados, porque desde lo 
teórico y empírico tendríamos que reconocer el tránsito y acomodamiento que están viviendo las sociedades y los sujetos que las constituyen. En el caso de los usos de la noche y los tales sitios llamados antros, habría que subrayar la presencia significativa de las mujeres en los distintos lugares analizados; ello sin duda supone una sensibilidad distinta para usar, hacerse presente y construir los sentidos propios de la diversión a partir de sus propias historias genéricas. Si la presencia de mujeres en los videobares, discos, salones de baile tropical, solas, en grupo o acompañadas; adolescentes, jóvenes o adultas no supone una emergencia en las formas típicas en que las generaciones anteriores construían su vivencialidad nocturna, no sabría como llamarle.

En este sentido, la dimensión virilizante que, sin duda, siguen teniendo estos lugares, no ha impedido una ruptura en las lógicas tradicionales con la llegada de estos personajes. La suma de personajes nocturnos trasngeneracionales y heterogenéricos en un antro, debe llevarnos a la construcción de otras metáforas para entender las ocurrencias, los mecanismos y los procesos de territorialización que sus estancias llegan a tener. Ver un tipo de cuarenta años compartir con un joven de dieciocho una mesa en un bar, no debe sorprendernos, pero si a ello se agrega una jovencita que resulta ser la novia de él, debe de llevarnos a una lectura distinta. En este mismo tenor, ver a una familia hasta altas horas de la noche departiendo en un salón de baile, donde chiquillos de diezdoce años, junto a la abuela y los novios de las hijas gozan desde sus marcos de referencia, nos lleva a reconocerlo como una forma emergente de diversión. Ya los señores con sus amigos o con sus amantes no son los únicos sujetos visibles en los antros, también las señoras de casa con sus amigas que salen a tomar la copa o a ligar cuando hay lugar y oportunidad para esto.

Así pues, en esta investigación pasamos de tomar cervezas, platicar, bromear, bailar y dejar escapar la mirada tras esas figuras corpóreas que se mueven apretujadas entre tantas, a entender en todo ello una elaborada trama de lo social, donde la sexualidad cabalga en el movimiento de traseros y caderas de quienes acuden a una disco; o donde un "inmaculado" erotismo devela una coreografía que aproxima o distancia cuerpos en medio de penumbras que provocan la imaginación masculina; o donde la identidad y los procesos de territorialización vienen acompañados de los recuerdos hechos sonidos; o donde los marcadores juveniles suponen una puesta en común generacional, matizada por indicadores mediacionales que revientan en los sitios desde los cuales 
se hacen visibles las maneras en que estos grupos hacen evidente lo bebido en los discursos mediáticos. Es decir, en una "cierta" manera de configurar una gramática cultural, donde la interacción entre agentes sociales, los momentos y acciones que establecen, devienen procesos complejos de significación y sentido.

Para finalizar, creemos que siempre será importante señalar que las características ontológicas, epistemológicas, axiológicas de investigaciones como éstas, supone un nivel de involucramiento del investigador que deviene un problema relacional entre el sujeto y el objeto de conocimiento. Ante lo que esto conlleva, es importante un descentramiento de nuestra mirada y de nuestra condición de sujeto social, para asumir una postura reflexiva, propia de una actitud fenomenológica capaz de desarrollar una mirada discrecional, sensible, sistemática. Cosa nunca fácil, en particular cuando la experiencia se va construyendo en el camino, donde los tropiezos, raspones y ganas contingentes, son los eternos acompañantes de una noche negociada.

En este sentido, las dificultades que tuvimos fueron muchas. Desde aquella que tiene que ver con el acceso a los universos trabajados, los físicos y los simbólicos, a los procesos de interacción procurados durante el tiempo de observación. Aquí habríamos de referir los sitios erotivirilizados, pues siempre nos llevaron por los límites propios de la observación participante y la toma de distancia de una pretensión objetiva. También habríamos de señalar que en el caso de la estrategia de abordaje, al inicio se planteó la posibilidad de desarrollar entrevistas a profundidad; sin embargo, sobre el propio proceso hubo un giro tecnológico en virtud de la dificultad para generar los tipos de encuentros dialógicos y dialogados con los sujetos que para la investigación considerábamos importantes. Impedimentos que iban de los horarios disponibles por parte de ellos para poder facilitar tales entrevistas (casi todas las citas eran para las 4 o las 6 de la mañana), a los tiempos de administración del programa. La suma de estas dificultades temporales también tenían que ver con los momentos que, como investigadores, disponíamos, ya que los compromisos laborales impedían una mayor movilidad. Al final del trabajo, logramos tener sus voces con entrevistas etnográficas.

Entendemos que todo proceso de investigación pasa por estadios de esta naturaleza. Finalmente, las realidades a las que nos enfrentamos quienes hacemos una apuesta metodológica como la que aquí operamos, las asumimos en su emergencia, su dinamismo, su flujo perenne, su condición hologramática; algo que nos hace mover sobre dimensio- 
nes complejas, que aquí nos dimos a la tarea de analizar, siempre procurando que la comunicación fuera el eje transversal y el dispositivo estratégico para hacer inteligible los lugares, las formas, las acciones y los sujetos con quienes tuvimos ocasión de trabajar. Como aprendices de investigadores, esto fue profundamente significativo, sobre todo por enfrentarnos por primera vez a un proceso de sistematización antes no vivido. Queden pues estos dichos...

\section{REFERENCIAS BIBLIOGRÁFICAS}

Bourdieu, Pierre (1990) Sociología y cultura. México: CNCA/Grijalbo. (1987) Cosas dichas. Buenos Aires: Gedisa.

De Bono, Edward (1996) Lógica fluida. La alternativa a la lógica tradicional. México: Paidós.

De CerteAu, Michel (1996) La invención de lo cotidiano. 1 artes de hacer. México: UIA/ITESo/Centro de Estudios Mexicanos y Centroamericanos.

CAStells, Manuel (1974) La cuestión urbana. México: Siglo xxi Editores.

Galindo CÁCERes, Jesús (1999) Sabor a ti. Metodología cualitativa en investigación social. México: Universidad Veracruzana.

GeERTZ, Clifford (2000) La interpretación de las culturas. España: Gedisa.

Giddens, Anthony (1995) La constitución de la sociedad. Bases para la estructuración. Buenos Aires: Amorrortu.

Giménez Montiel (s/f) Territorio y cultura. Colima: Universidad de Colima. (1997b) "Materiales para una teoría de las identidades sociales", Frontera Norte, vol. 9, núm. 18, julio-diciembre, México.

(s/f) Territorio, cultura e identidades. La región sociocultural. México: Instituto de Investigaciones Sociales de la UNAM.

GonZález, Jorge A. (1994) Más (+) cultura(s). Ensayos sobre realidades plurales, col. Pensar la cultura, $1^{\text {a }}$ edición. México: CNCA. 
Jiménez, Armando (1999) Lugares de gozo, retozo, ahogo y desahogo en la ciudad de México. Cantinas, pulquería, hoteles de rato, sitios de prostitución, cárceles. México: Océano.

LefeBVRe, Henri (1978) El derecho a la ciudad, $4^{\text {a }}$ edición, col. Historia/ciencia/ sociedad. Barcelona: Península.

Lezama, José Luis (1998) Teoría social, espacio y ciudad. México: El Colegio de México.

Reguillo, Rossana (1995) "Pensar la ciudad desde la comunicación. Un ejercicio necesario", Campo académico de la comunicación: hacia una reconstrucción reflexiva. México: $\mathrm{CNCA} / \mathrm{ITESO}$.

(s/f) "Los mitos gozan de cabal salud: el horizonte de las creencias colectivas en la modernidad mexicana", artículo del proyecto de investigación Mitologías urbanas (mimeo), México.

Ricoeur, Paul (1996) Sí mismo como otro. México: Siglo xxi Editores.

SchUTz, Alfred (s/f) El problema de la realidad social. Argentina: Amorrortu.

Silva, Armando (1992) Imaginarios urbanos. Bogotá y Sâo Paulo: Cultura y comunicación urbana en América Latina. Colombia: Tercer Mundo Editores.

SPradley, James (1980) Participant observation. Nueva York: Holt, Rinehart and Winston.

Taylor y Bogan (s/f) Introducción a los métodos cualitativos de investigación. Buenos Aires: Paidós.

Thompson, John B. (1996) Ideología y cultura moderna, 2a edición. México: UAM-Xochimilco. 